\title{
Registro/documento: fotografia na obra de arte contemporânea ${ }^{1}$
}

\author{
Record/document: Photography in the \\ contemporary work of art
}

\author{
Bruno Cesar RODRIGUES 2 \\ Giulia CRIPPA ${ }^{3}$
}

\begin{abstract}
Resumo
O presente artigo tem como intuito apresentar algumas discussões quanto aos registros em arte contemporânea, em especial a fotografia. Esses registros são musealizados como documento ou como obra de arte? Embora possuam a função documental, eles muitas vezes podem ser considerados uma extensão da obra de arte registrada, bem como podem, em certa medida, tornar-se autônomos e ser considerados outra obra de arte ou a obra de arte em si. Isso, muitas vezes, vai depender da função que Ihes é atribuída ou mesmo da intenção do artista. Trata-se de uma pesquisa de cunho qualitativo com base em estudo exploratório, a respeito do qual se apresentam algumas considerações apontadas na literatura proposta. A partir dos estudos realizados, observa-se que as fotografias, um dos meios de registro mais utilizados em arte contemporânea, possuem a dupla função de ser registro/documento e obra de arte. Desse modo, pode haver dúvida no momento da guarda.
\end{abstract}

Palavras-chave: Arte contemporânea. Documento. Fotografia. Musealização.

\begin{abstract}
The purpose of this article is to present discussion regarding records in contemporary art, especially photography. Are these records musealized as documents or works of art? While having a documentary function, they can often be considered an extension of the registered artwork, as well as become autonomous to some extent, be considered other artwork or the artwork itself. This often depends on their assigned function or even on the artist's intention. This is a qualitative research based on an exploratory study about which we present some considerations outlined in the proposed literature. Based on the studies, we observe that the photographs, one of the most used means of recording in contemporary art, have the dual function of record/document and work of art. Thus, there may be doubts at the time of the guard.
\end{abstract}

Keywords: Contemporary art. Document. Photograph. Musealization.

\section{Introdução}

Inicia-se o presente artigo com algumas questões: Qual a função da fotografia de uma obra de arte contemporânea? Esse tipo de registro serve unicamente para relembrar a intervenção artística realizada ou alguma

\footnotetext{
1 Artigo elaborado a partir do projeto de doutorado de B.C. RODRIGUES, intitulado "Arte contemporânea, museu e arquivo: desafios da ciência da informação". Universidade de São Paulo, 2017.

2 Universidade de São Paulo, Escola de Comunicações e Artes, Departamento de Biblioteconomia e Documentação. São Paulo, SP, Brasil.

3 Universidade de São Paulo, Faculdade de Filosofia, Letras e Ciências de Ribeirão Preto, Curso de Ciências da Informação e da Documentação. Av. Bandeirantes, 3900, Monte Alegre, 14040-901, Ribeirão Preto, SP, Brasil. Correspondência para/Correspondence to: G. CRIPPA. E-mail: < giuliac@ffclrp.usp.br>. Apoio: Fundação de Amparo à Pesquisa de São Paulo (Processo n 2013-04951-0). Recebido em 22 de dezembro de 2015, versão final reapresentada em 27 de abril de 2017 e aprovado em 29 de maio de 2017.
}

Como citar este artigo/How to cite this article

Rodrigues, B. C.; Crippa, G. Registro/documento: fotografia na obra de arte contemporânea. Transinformação, v. 30, n. 1, p. 15-26, 2018. https://doi. org/10.1590/2318-08892018000100002 
obra de arte efêmera, um dia exposta? Ela passa por processo de musealização com intuito documental ou artístico? Este artigo tem como objetivo abordar esses questionamentos, discutindo acerca da musealização dos registros fotográficos, bem como das funções estética e/ou documental que lhes são atribuídas. Desse modo, estabelece-se como ponto de partida que toda fotografia de determinada obra de arte contemporânea é um registro que pode vir a ser musealizado, tanto como documento quanto como obra de arte.

É importante ressaltar a utilização dos termos "registro" e "documento" no texto que segue. O primeiro será considerado o ato de registrar algo, sem, necessariamente, o intuito de documentar: fotografar uma obra de arte sem pensar que tal registro possa ser um documento da mesma; fotografar aleatoriamente. Já o segundo termo indica o registro com função documental: a fotografia que foi feita com o intuito de documentar a obra de arte contemporânea e sua entrada na instituição enquanto documento; fotografar sistematicamente. Quando o registro/documento for tratado pela sua função estética, será considerado como obra de arte. Tanto o registro quanto o documento são suportes físicos (ou não físicos) que contêm informações. No entanto, o registro ainda deverá passar por um processamento dessas informações.

O texto proposto constitui uma pesquisa de cunho qualitativo com base em estudo exploratório. Parte-se da hipótese de que os registros fotográficos desafiam os fazeres do profissional da informação no que concerne à guarda, uma vez que possuem dupla função: documental e estética. Conclui-se que o que vai definir se a fotografia é documento ou obra de arte vai depender dos interesses do fotógrafo/artista; ou melhor, da sua intencionalidade com relação ao registro. Portanto, a fotografia será obra de arte ou documento, dependendo da intenção do fotógrafo. Por outro lado, sua guarda e preservação, dependerão muito mais das políticas institucionais, que definem as regras dos fazeres, do que da sua definição enquanto memória da exposição ou obra de arte. Para a criação de tais regras devem ser considerados inúmeros quesitos, como catalogação, conservação e recuperação. Unir os procedimentos da museologia, da arquivologia e da biblioteconomia também pode auxiliar na melhor guarda desses registros.

Não se pretende, com isso, estabelecer normas procedimentais, mas apenas indicar possibilidades a serem refletidas. O maior propósito é apresentar algumas considerações e levantar alguns questionamentos acerca do assunto, de modo a contribuir com as discussões a respeito do assunto.

\section{Procedimentos metodológicos}

Conforme indicado, o presente artigo é de cunho qualitativo e pauta-se na articulação da literatura selecionada e apresentada. Os estudos exploratórios, como este que segue, ainda que não tão aprofundado, são ferramentas que "permitem ao pesquisador aumentar sua experiência em torno de determinado problema. O pesquisador parte de uma hipótese e aprofunda seu estudo nos limites de uma realidade específica [...]" (Triviños, 1987, p.109). Desse modo, partiu-se da articulação dos discursos provenientes das referências consultadas, com o intuito de fornecer breves definições e elementos condizentes com a realidade e que justifiquem os resultados alcançados, ou mesmo indicar o caminho percorrido. Embora não sejam dados inéditos, acredita-se na importância do debate acerca desse tema.

A indagação aqui apresentada parte da hipótese de que os registros fotográficos, que possuem tanto função estética quanto documental, desafiam os profissionais da informação no que condiz à sua guarda, quando o tema imagético é uma obra de arte contemporânea efêmera. Outro fator é que toda fotografia desse tipo de obra é um registro que pode vir a ser musealizado como documento ou como uma obra de arte autônoma. Assim, este estudo aproxima os dizeres dos textos consultados e, a partir deles, tenta refletir acerca das possibilidades inerentes aos fazeres desses profissionais. Os resultados alcançados são provenientes também de observações simples (Gil, 1999), 
as quais não interferiram na rotina das instituições de arte visitadas, e de conversas informais com profissionais da área, além de relatos coletados em seminários e simpósios.

\section{Resultados e Discussão}

\section{Arte contemporânea como arquivo da contemporaneidade}

Uma das características principais da arte contemporânea é a multiplicidade de suas formas e manifestações. Isso significa, entre outros fatores, que suas técnicas e seus materiais expressivos são os mais diversos, muito além do elenco e do repertório de qualquer tradição artística anterior (Archer, 2001). Na criação de suas obras, os materiais clássicos são substituídos ou mesclados com outros de uso industrial, doméstico, ou com objetos de uso comum, organizados das maneiras mais inesperadas e até mesmo contraditórias.

O artista que operava no âmbito da arte dita tradicional possuía um conhecimento íntimo da natureza dos materiais utilizados. A partir do século XIX, assiste-se a uma importante mudança, com o aparecimento das cores industrializadas. O desenvolvimento tecnológico passa a ter um importante papel na expressão artística, fornecendo novos materiais até chegar aos dias de hoje. A chamada arte pobre (arte povera), por exemplo, descobre as propriedades expressivas de objetos não artísticos feitos em materiais comuns como papel, vidro, tecido, chegando aos materiais da própria natureza, tais quais a terra, a grama, as pedras, a madeira, as folhas (Gombrich, 2013).

O plástico torna-se, ao mesmo tempo, mídia, suporte e objeto da criação artística contemporânea. Produzem-se obras de substâncias perecíveis, sujeitas a mudanças: gorduras animais, açúcar, chocolate, chegando à obra de arte constituída pelo próprio artista que exibe a si próprio: seu corpo e suas ações se tornam representação física e simbólica. Dessas obras todas só permanecem seus registros por meio da documentação fotográfica ou em vídeo, e é esta que se torna o novo objeto alvo de organização e preservação nas instituições.

No caso da arte contemporânea, portanto, ao lado das necessidades de preservação da ampla variedade de materiais, é necessário pensar em como preservar a ação do próprio artista, que deve ser, assim, amplamente documentada. Nesse sentido, um dos aspectos metodologicamente mais complexos na preservação da arte contemporânea é o setor, cada vez mais amplo e diversificado, das obras efêmeras e conceituais (Freire, 1999).

Na arte conceitual podem ser diferenciadas tipologias e níveis de expressão: desde aquelas que materializam as ideias em objetos e formas até aquelas que tendem ao desaparecimento do valor material da obra, em que o projeto adquire um valor maior em relação à realização. Em seu extremo de negação do objeto, a arte conceitual pode tornar-se completamente imaterial. Há, assim, diferenças importantes entre as obras cujo projeto artístico permite sua duplicação, portanto sua reprodução, e obras que não podem ser repetidas (um bom exemplo disso é representado pelas embalagens de Christo e Jeanne Claude).

Pertencem à categoria de arte enquanto ideia as obras realizadas com materiais perecíveis: os happenings e as performances, destinadas a uma duração que coincide com sua representação (Melim, 2008), bem como a land art e as obras ambientais, em que o ambiente e a natureza entram como constituintes da própria obra (Archer, 2001). Trata-se de uma arte dinâmica, sujeita ao tempo e às mutações, em sua própria essência, portanto, não permanentes.

As obras efêmeras, as obras que não podem ser reproduzidas, por exemplo porque ao longo do tempo os materiais originários saem de produção, podem ser preservadas e conhecidas, em primeiro lugar, por meio da documentação iconográfica e em audiovisual, ao lado dos projetos, desenhos e escritos dos próprios artistas idealizadores. Uma documentação completa da obra no momento de seu aparecimento/exposição pode permitir a expectativa de que, mesmo na ausência das instruções do artista quanto à realização de seu projeto, ela possa ser 
reproduzida ou replicada de maneira fiel ao original. Particularmente no caso das performances e dos happenings, os cenários, costumes e objetos utilizados compõem a documentação completa da obra.

Considerando que o problema principal proposto por essa tipologia de obras é o do próprio reconhecimento enquanto obras de arte, dificultando, assim, a coleta tempestiva de todas as partes dessa documentação necessária para a transmissão de sua memória, a documentação textual, iconográfica e audiovisual adquire um papel fundamental não somente como instrumento de preservação, mas também como de criação das próprias obras.

A necessidade de estudar todas as tonalidades da expressividade artística, o desejo de documentar e de conhecer as obras contemporâneas levaram, nos últimos anos, a uma série ampla de iniciativas voltadas para a definição de metodologias mais eficazes para abordagem da documentação, com a clara consciência de que museus e coleções necessitam, cada vez mais, acolher obras que não foram criadas para durar.

Torna-se claro que réplicas e (re)proposições dessas obras efêmeras, dos happenings, das performances e das instalações, adquirem, na maioria dos casos, somente esse valor documental, isto é, de testemunha histórica e não mais artística. Todavia, parece que essa postura arquivística das instituições é de importância fundamental, na medida em que em tempos rápidos torna-se difícil entender o ambiente em que se desenvolveram determinados movimentos artísticos expressivos. Em vista disso, é necessário preservar para permitir a reconstituição da memória de obras que já não existem mais ou que estão destinadas, em breve, a desaparecer de sua forma original, bem como de obras que não possuem materialidade. Contudo, na composição da documentação fotográfica entra uma série de questões ligadas à própria natureza da fotografia, que se tentará abordar a seguir.

\section{Fotografia, documento e arte contemporânea}

Rouillé (2009) explica que a história da fotografia está cheia de tomadas de posição, seja a favor ou contra sua introdução no território das artes. Discutia-se muito a sua essência artística, pois se tinha como conceito artístico a obra que era feita manualmente, e não por meio de uma máquina. Muitos artistas utilizaram a fotografia como ferramenta para criação de suas obras. Delacroix, por exemplo, desenhava utilizando-se de provas fotográficas que realizava junto com Eugène Durieu, evidencia o autor. Para o artista, a máquina fotográfica era um objeto didático do qual fazia uso, fosse para realizar seus desenhos de modo mais exato, fosse para conhecer as obras dos grandes mestres.

[...] a fratura entre a arte e a fotografia seria estrutural: enquanto a célebre 'teoria dos sacrifícios' constitui um dos critérios fundamentais da arte, a fotografia não pode controlar a profusão de detalhes; enquanto a arte consiste em escolher o que lhe convém e repudiar o que não Ihe convém, a fotografia apenas registra; enquanto a pintura é da ordem da construção, à fotografia competem a captação, a coleta e o corte. [...] O fotógrafo 'tira', a pintura compõe; a tela é uma totalidade, a fotografia é apenas um fragmento (Rouillé, 2009, p.243).

Dubois (1994) declara que no século XIX a fotografia aspirava à arte, enquanto no século XX é a arte que vai ao encontro das lógicas fotográficas, sejam elas formais, conceituais, de percepção ideológica ou quaisquer outras. O ponto de ancoragem, aponta Dubois (1994, p.254), estaria "[...] no movimento 'pictorialista' (1890-1914), que assinala o ponto culminante desse desejo que a fotografia tinha de 'se fazer pintura' e sua impossibilidade teórica e prática". Outros pontos seriam, segundo o autor, as obras de Marcel Duchamp, os pioneiros da abstração El Lissitsky e Malévitch, além do dadaísmo e surrealismo.

Com o advento da fotografia houve um choque entre ela e os artistas; não por medo de uma possível concorrência, mas pelo receio da abertura de outro funcionamento da arte, afirma Rouillé (2009). A fotografia veio ameaçar a produção artesanal da imagem, processo que era lento e minucioso, pois ela não cria, não fabrica a imagem: ela escolhe, ela enquadra. Cotton (2013) cita que quase dois séculos após o surgimento dessa tecnologia, ela chegou à maioridade e se tornou uma forma de arte contemporânea, sendo acolhida pelo campo da arte como 
suporte legítimo. Conforme expõe Dubois (1994), num primeiro momento a intervenção fotográfica no campo artístico é de arquivamento, como suporte documental do trabalho realizado pelo artista, e, depois passa a ser parte integrante dos projetos de muitos deles. Ou seja, a fotografia não só podia afetar como afetou o processo de criação da arte quando surgiu. Embora fosse criticada, ela foi muitas vezes utilizada como ferramenta na produção artística, ou, juntamente com outros materiais, como vetor da arte. É somente na década de 1980 que ela se torna um dos principais materiais da arte contemporânea (Rouillé, 2009).

Um ponto a ser observado é que a fotografia se posiciona principalmente como documento e não apenas no campo artístico, seja apenas no sentido informativo, seja no sentido de prova ou evidência (Krauss, 2002). Isto é, em artes, os documentos podem auxiliar tanto na autenticação da obra quanto na sua compreensão, ou mesmo representar "como ela foi construída ou apresentada, [...] quais processos participaram de sua concepção e de sua realização, de como foi pensada por seu autor e também do modo como foi recebida" (Fervenza, 2009, p.47). A fotografia, então, surgiu como uma escrita de luz que envolve o estado físico e químico e que serve como dispositivo de registro da realidade quando não é manipulada com alguma intenção.

Uma problemática existente no campo das artes, que persiste desde a primeira metade do século XX, principalmente em uma parte significativa da produção artística, é a delimitação quanto à "separação entre o que é obra e outros elementos a ela relacionados, como a documentação e seu registro, [que] não está necessariamente ou nitidamente delimitada" (Fervenza, 2009, p.48).

Na concepção da documentalista francesa Suzane Briet (Buckland, 1991, 1997), a fotografia enquanto registro físico de um fato, sob o aspecto de prova, é um documento. Por exemplo, as estrelas no céu não são documentos, mas sua fotografia é - pelo fato de possuir informações, de ser informativa. Mesmo que produzida com fins artísticos, a fotografia também possui informações, e, enquanto documento (e não arte), ela é interpretada de forma mais técnica, menos flexível e menos abstrata. Em certa medida a fotografia enquanto documento pressupõe que a informação seja imutável e compreensível da mesma forma por todos. Por sua vez, a fotografia produzida com intuito artístico é passível de interpretações variadas, não havendo uma resposta única para o que a ela representa. Mas é fato que a mesma fotografia pode ser tratada das duas formas em contextos distintos.

Uma das grandes funções da fotografia-documento terá sido a de erigir um novo inventário do real, sob a forma de álbuns e, em seguida, de arquivos. O álbum, enquanto mecanismo de reunir e tesaurizar as imagens; a fotografia, enquanto mecanismo para ver (óptico) e para registrar e duplicar as aparências (químico). Assim, esse inventário fotográfico do real constituiu se no cruzamento de dois procedimentos de tesaurização: o das aparências, pela fotografia; e o das imagens, pelo álbum e pelo arquivo (Rouillé, 2009, p.97).

Rouillé (2009, p.98) destaca que "a primeira grande máquina de documentar o mundo e amealhar suas imagens" foi a união "fotografia-álbum". A junção entre "fotografia documento" durou por quase um século antes dos arquivos. Ele ainda sustenta que a "fotografia-documento" tinha "como horizonte o arquivamento", e que mudava a escala das coisas ampliando-as ou reduzindo-as. O uso das fotografias tem como principais funções, em seu início, inventariar, arquivar e promover uma submissão simbólica, obedecendo "a uma verdadeira compulsão de exaustividade, a uma veleidade de registro total do real". Como explica Dubois (1994, p.25, grifos do autor), a fotografia é vista com credibilidade como aquela que representa o real de forma fidedigna pela "[...] consciência que se tem do processo mecânico de produção da imagem fotográica, em seu modo específico de constituição e existência: o que se chamou automatismo de sua gênese técnica". Isso significa, complementa o autor, que a fotografia é vista como aquela que não pode mentir, pois a necessidade que se tem de ver para acreditar é plenamente satisfeita com a fotografia. Por isso, ela é vista como prova daquilo que representa em sua superfície.

A "fotografia-documento" teve papel importante na sociedade, pois contribuiu "para a expansão da área do visível e também para o aumento do espaço de trocas, para a dilatação dos mercados, para o alargamento da zona de intervenções militares ocidentais" (Rouillé, 2009, p.99). A partir da fotografia intensificaram-se as missões 
fotográficas com interesses científicos. O que antes era realizado por desenhistas, gravuristas e outros profissionais, com a câmera fotográfica passou a ser realizado por uma única pessoa e com a certeza de uma imagem mais fidedigna, assim como o trabalho tornou-se mais rápido e menos custoso, explana o autor.

Muitas das vezes as missões fotográficas eram associadas às operações militares, mas com o intuito de levar para o museu os registros de lugares longínquos, com interesses e curiosidades privadas, ou para constituir o que Disdéri (Rouillé, 2009, p.100) denominou "enciclopédia universal da natureza, das artes e da indústria". Nesse ponto, a fotografia atinge outro plano, que não se relaciona mais ao da captura, mas ao do depósito, ao da coleta, ao da tesaurização, que envolve o museu, o álbum e o arquivo, com o objetivo de acumular e conservar o que denominavam "vestígios de ontem" e "fragmentos atuais e de outros lugares":

Diante do resplendor do mundo, de sua aceleração, de sua dilatação, diante da desordem causada pela consciência recente da expansão de outros lugares e do inacessível, diante da confrontação reiterada com o novo e o diferente, ou seja, diante da dificuldade crescente em manter uma relação física, direta e sensível com o mundo, a fotografia-documento desempenha um papel de mediação (Rouillé, 2009, p.100).

A fotografia fez com que as pessoas se familiarizassem com a exterioridade de outros lugares, mas, como menciona Rouillé (2009), a relação que se tinha com essa exterioridade era delegada ao fotógrafo, e as relações eram substituídas pela imagem e não mais se estabeleciam pelo contato direto. Aos poucos o mundo era transposto em imagens para os álbuns e arquivos. Aqui se consegue entender um pouco a fotografia como "espelho do real", conforme aludido por Dubois (1994): a fotografia que retrata mimeticamente a realidade, servindo como um espelho do mundo.

Todo esse processo de transposição do mundo em imagens aprofundou-se cada vez mais com o passar dos tempos, assinala Rouillé (2009). Todos os álbuns como os arquivos, e os dispositivos que vieram depois, nunca foram receptáculos passivos. Eles agrupavam, acumulavam, conservavam e arquivavam não sem propor visões e ordenar simbolicamente o real: a "fotografia-documento", juntamente com o álbum e o arquivo, tinha a função de ordenar o mundo. "Nesta vasta empreitada, a fotografia-documento e o álbum (ou arquivo) desempenham papéis opostos e complementares: a fotografia fragmenta, o álbum e o arquivo recompõem os conjuntos. Eles ordenam" (Rouillé, 2009, p.101). Enquanto a reordenação era realizada de modo artificial e seguindo interesses daqueles que as faziam, a interpretação daqueles que acessavam os álbuns e os arquivos era individual. Mesmo que houvesse e/ou ainda haja algum direcionamento no modo de perceber o que se expõe, o indivíduo permanece livre para interpretar segundo seus referenciais o que lhe é exposto.

Se a fotografia disputava espaço e reconhecimento no âmbito artístico, no campo científico sempre teve seu lugar ao sol:

A fotografia - que reproduz mais rapidamente, mais economicamente, mais fielmente do que o desenho, que registra sem omitir nada, que dissimula as imprecisões da mão, que, em resumo, troca o homem pela máquina - impõe se imediatamente como a ferramenta por excelência, aquela que a ciência moderna necessita. E continuará sendo assim até à Segunda Guerra Mundial (Rouillé, 2009, p.109).

A fotografia contribui para a modernização do conhecimento e do saber científico, mas esse processo de modernização extingue toda a subjetividade dos documentos, o que significa "registrar, sem esquecimento nem interpretação, para autenticar, ou para substituir, o próprio objeto", salienta Rouillé (2009, p.109). Sob este ponto de vista, o autor apresenta uma separação entre o que é a fotografia documental e a fotografia com intuitos artísticos. Assim: a fotografia como processo mais mecanicista é considerada como documental, enquanto a fotografia com intenções de interpretação do que se fotografa, como transmissão de sentidos e não apenas informação, é mais humanística, logo, artística.

As fotografias são versáteis, de modo a apresentar tanto a função documental quanto a estética. Enquanto documento, às vezes pode ser considerada como uma extensão da obra de arte registrada, bem como tornar-se autônoma a ponto de ser considerada outra obra de arte ou a obra em si. Mesmo no sentido estético ela possui a 
função documental, principalmente se se considera que, na arte conceitual, o processo de criação artística começa muito antes que a câmera enquadre e fixe a imagem a ser registrada, como demonstra Cotton (2013). Desse modo, a câmera fotografa um ato performático, mas apresenta ao espectador apenas a imagem e não o ato físico, completa a autora. Também na concepção de Meneses (1994), da obra de arte considerada como um "documento plástico", pode-se inferir essa função documental da fotografia enquanto obra.

Dubois (1994) destaca o uso das fotografias pelos artistas conceituais, da arte ambiental, do happening, da body art e da performance, como secundário, num primeiro momento. Isto é, entende a fotografia como forma de memorização do ato, ou seja, como documento e arquivo da ação - mas que, depois, passa a integrar o processo criativo a ponto de a concepção se dar considerando as características do dispositivo de captura de imagens. Para Cotton (2013), a fotografia possui momentos distintos. A autora afirma que, no âmbito da prática da arte conceitual, a ênfase recai muito mais na importância artística (que reside no ato retratado pela fotografia) do que na exaltação da atividade fotográfica virtuosa, que rotula alguns como mestres fotógrafos:

A arte conceitual usou a fotografia como meio de transmitir ideias ou atos artísticos efêmeros, fazendo as vezes do objeto de arte na galeria ou nas páginas de livros e revistas de arte. Essa versatilidade do status da fotografia, como documento e evidência da arte, tem uma vitalidade intelectual e uma ambiguidade bem usadas pela fotografia contemporânea (Cotton, 2013, p.22).

Podem-se utilizar como metáfora os comentários de Rouillé (2009) quanto à diferenciação de "vista" e "paisagem" para diferenciar arte e documento, na medida em que a ideia de vista corresponde à de documento, e a de paisagem à de arte:

A paisagem depende do julgamento do gosto; a vista, do julgamento prático. Na vista, o referente prevalece sobre o indivíduo que a realiza, a descrição suplanta a expressão. A vista é denotativa. Ela não é destinada à parede da exposição, mas à publicação e ao arquivamento. A vista descreve, propõe um conhecimento. Não a contemplamos, não a consultamos: servimo-nos dela (Rouillé, 2009, p.112).

Observa-se, então, que a fotografia enquanto registro/reprodução automática das coisas, dos fatos, está mais para documento, ou melhor, documentação, do que para arte. A arte, de certo modo, requer outros sentidos diferentes do ato de reproduzir automaticamente com o fim de registrar os fatos. Acredita-se que, em geral, as fotografias são selecionadas como documentos e adentram os museus como pontos de vista das obras. Como não está claramente definida a delimitação entre o que é obra ou documentação, como salientado por Fervenza (2009), uma das consequências é que as instituições culturais, as galerias e os museus demonstram não estar preparados para lidar com essa situação.

A fotografia de uma obra de arte, conforme os interesses do fotógrafo, pode tanto denotar um trabalho de documentação, de composição de um catálogo de artista ou de exposição a se realizar, quanto uma nova obra de arte. Crimp $(2005$, p.6) descreve uma fotografia de Louise Lawler, na qual a fotógrafa "apresenta um trabalho de Degas, mas o faz por meio de uma representação - reformulando-o, cortando-o [...]". Esta fotografia não é um documento de uma exposição, não foi realizada para compor um catálogo. Ela é uma representação com intencionalidade artística da fotógrafa/artista. Essa fotografia é uma obra de arte, o que, na concepção de Benjamin (1994, p.177), não seria, pois, para ele,"Fotografar um quadro é um modo de reprodução; fotografar num estúdio um acontecimento fictício é outro. No primeiro caso, o objeto reproduzido é uma obra de arte, e a reprodução não o é".

Para complementar, Dubois (1994) indica que a fotografia é utilizada nas artes de maneiras diversas. Na arte conceitual, por exemplo, ela muitas vezes faz intervenções diretas no processo artístico, mesmo que não possua uma atuação em primeiro plano. Em "Uma e Três Cadeiras", de Joseph Kosuth, ela é representada na mesma condição que o objeto (a cadeira real) e a representação textual (verbete retirado do dicionário e ampliado).

É com base na arqueologia foucaultiana que Crimp (2005, p.14) tece uma teoria do pós-modernismo nas artes visuais, na qual "propõe que a moderna epistemologia da arte é um resultado do isolamento da arte nos museus onde a arte foi apresentada como autônoma, alienada, algo à parte, submetendo-se apenas à própria 
história e dinâmica internas". A fotografia colaborou para estender esse idealismo enquanto instrumento de reprodução da arte. No entanto, ela não foi aceita no museu e na história da arte, porque:

[...] aponta para um mundo que está fora de si mesma. Assim, quando se permite que a fotografia entre no museu como uma arte como as demais, a coerência epistemológica do museu desmorona. O "mundo de fora" é admitido, revelando-se que a autonomia da arte é uma ficção, uma construção do museu (Crimp, 2005, p.14).

Com o exposto, Crimp (2005) apresenta o conflito instaurado pela fotografia ao tentar adentrar o museu como obra de arte. O autor destaca que ela era apenas um veículo para que as obras de arte adentrassem o "museu sem paredes" de André Malraux. Até esse ponto, defende Crimp (2005, p.52), havia coerência. "Mas, uma vez que a própria fotografia passa a ser um objeto a mais, restabelece-se a heterogeneidade no coração do museu, e suas pretensões de conhecimento estão condenadas ao fracasso".

Para Costa (2009), os registros fotográficos não tratam apenas de documentação. Eles tanto capturam a experiência que foi realizada e não existe mais, tornando a visível novamente, como levantam temáticas que se relacionam ao estético, à poética e às questões plásticas.

[Os registros fotográficos] tornam visíveis o status da arte no mundo contemporâneo, valendo-se de uma atuação, de uma atualização da obra em local específico. Abordam o problema da guarda e da memória; do suporte e da transferência de escrituras e de afetos rivais, assim como a função da autoridade na arte (Costa, 2009, p.83).

Segundo o mesmo autor, vivenciar obras que se utilizaram de materiais efêmeros e outras situações só é possível por meio dos registros ou presenciando-as no momento em que ocorreram. Por outro lado, "parte da arte processual e da crítica institucional tem insistido no registro como mera documentação, sem valor de arte ou de objeto artístico autônomo" (Costa, 2009, p.84).

Costa (2008) afirma que a fotografia desafia os profissionais de documentação e curadoria nos museus de arte, uma vez que não estão bem preparados para lidar com a condição múltipla inerente a ela, nem com seu caráter híbrido.

Dois pesos, duas medidas: como compatibilizar, em um mesmo acervo, o tratamento dado à fotografia considerada artística, segundo a teoria modernista, e o tratamento conferido ao registro fotográfico, muitas vezes precário, de uma ação artística? Do ponto de vista tipológico, ambas são obras aparentemente idênticas, mas radicalmente distintas no que se refere ao processo de atribuição de valor artístico a que foram submetidas. Isso significa que ingressaram no acervo dos museus a partir de diferentes discursos de legitimação. O valor artístico, como sabemos, não se encontra materializado na cópia fotográfica em si e depende de atribuições fundamentadas em certas práticas sociais (Costa, 2008, p.167).

Como exemplo, Melim (2009) indica que algumas performances são realizadas diante das câmeras fotográficas ou filmadas para que sejam apresentadas ao público em um museu. Logo, esse registro é comumente visto como obra de arte, embora o sentido de performance seja o de uma ação realizada diante de um público. Nesse caso específico, não houve uma plateia para assistir à performance, e o documento é tanto a obra de arte quanto pode ser considerado a outra obra. Archer (2001) afirma que performance é uma ação que, com exceção dos poucos presentes quando de sua realização, vai existir para o público por meio de sua documentação, indicando, desse modo, que o registro enquanto documento é uma extensão da obra de arte realizada, dando-lhe uma sobrevida. Algumas vezes quem definirá se o registro é um documento ou uma obra de arte será o artista e seu interesse de exibição do mesmo.

\section{Musealização}

Ao tratar sobre o fato de as fotografias adentrarem os museus, pode-se pensar em termos de institucionalização e/ou musealização. Musealizar, em certa medida, é ingressar o objeto, seja físico ou conceitual, no 
museu, retirando-o de seu contexto original e dotando-o de uma nova função. Para Roque (2012, p.68), no museu de arte "a prevalência do conteúdo estético sobre os restantes atributos acentuou essa perda de sentido". Embora a autora não fale de museu de arte contemporânea, não se podem negar as propriedades estéticas dessa arte, motivo pelo qual o museu faz a sua guarda.

[... .] A musealização consiste em um conjunto de processos seletivos de caráter info-comunicacional baseados na agregação de valores a coisas de diferentes naturezas às quais é atribuída a função de documento, e que por esse motivo tornam-se objeto de preservação e divulgação. Tais processos, que têm no museu seu caso privilegiado, exprimem na prática a crença na possibilidade de constituição de uma síntese a partir da seleção, ordenação e classificação de elementos que, reunidos em um sistema coerente, representarão uma realidade necessariamente maior e mais complexa (Loureiro, 2011, p.2).

Para Nascimento (2013, p.45), "musealizar não diz respeito apenas a objetos mas, também, aos valores que animam esta operação política, científica e estética. E neste sentido, a musealização não diz respeito apenas ao museu mas às sensibilidades históricas, sociais e culturais". Para a autora, a reconstrução da memória e do passado são implicações controversas da musealização, pois esta manipula as evidências do passado. Portanto, o ato sistemático ou voluntário de musealizar as fotografias de obras de arte implica a seleção de uma memória e a institucionalização dessas obras. Por outro lado, trata-se aqui de fotografias de arte contemporânea, tida como arte do presente.

Costa (2008) afirma que até os artistas negavam a fotografia, mesmo que a utilizassem para realizar suas obras. No entanto, aos poucos, ela foi aceita. A autora elenca três estratégias que culminaram na inserção das fotografias nos museus de arte, ou melhor, em sua legitimação pelas instituições museológicas.

A primeira estratégia é considerada a institucionalização, pelo Departamento de Fotografia do Museum of Modern Art, na década de 1940, daquilo que denominavam "fotografia direta". Este mesmo departamento estabeleceria o que viria a ser fotografia artística. Essa assimilação da fotografia no museu se deu pela paradoxal transformação cultural:"o museu passou a valorizar a fotografia não enquanto 'imagem reprodutível' e versátil, mas enquanto 'objeto de coleção', pautado por valores como raridade, autenticidade, expressão pessoal e virtuosismo técnico" (Costa, 2008, p.133, grifos da autora).

Diferentemente da primeira, a segunda estratégia foi indireta e não direta, esclarece a autora. No caso, foi "por meio da pop arte, da arte conceitual e das diferentes práticas artísticas de caráter experimental desenvolvidas ao longo das décadas de 1960 e 1970" (Costa, 2008, p.133). Essa estratégia foi indireta porque os artistas que utilizavam a fotografia não buscavam discutir o seu status artístico. Por outro lado, para os artistas:

[... a a imagem fotográfica foi um instrumento privilegiado para colocar em xeque o estatuto tradicional da obra de arte. E foi no momento em que assimilou esses diferentes tipos de proposições artísticas que o museu acabou abrindo espaço, talvez inadvertidamente em muitos casos, a uma outra fotografia que não aquela considerada artística pelos cânones do modernismo (Costa, 2008, p.134).

Por fim, a terceira estratégia ocorreu a partir da década de 1980. É nesse período que os museus passaram a valorizar as fotografias que possuíam certo modelo pictórico baseado "no uso de planos frontais bem delimitados, no estabelecimento de diálogos com a tradição da pintura desde o Renascimento, e [que] materializa-se em fotografias em cor, de grande formato" (Costa, 2008, p.134).

Freire (1999), assim com Dubois (1994), destaca o fato de que a fotografia teve e ainda tem um papel importante nas obras de arte contemporânea, ultrapassando sua função inicial de documento. Muitas vezes a fotografia vinha depois da obra, com o intuito de apenas documentar. Aos poucos ela passou a ser parte constituinte da obra e de todo o processo de produção artística, tornando-se, algumas vezes, a obra final.

Como exemplo de uma obra que se representa por sua documentação devido à difícil observação de sua completude a não ser pela visão aérea, tem-se o Spiral Jetty, de Robert Smithson. A fotografia teve, e ainda tem, um papel muito importante no que se refere à sua exposição ou mesmo à mediação com o público. Não é possível 
trazê-la para o museu a não ser por meio do registro fotográfico. As fotografias tiradas quando a obra foi realizada e as atuais podem demonstrar os sentidos desenvolvidos pela Land Art sobre as alterações sofridas com a ação do tempo e da natureza, assim como pontuar a tomada da paisagem como objeto artístico (Dubois, 1994).

Outro artista bastante emblemático é Christo, juntamente com sua esposa Jeanne-Claude, cujas obras realizam alguma intervenção no ambiente e são, muitas vezes, temporárias, restando apenas os documentos compostos por projetos e fotografias que comprovam sua intenção e realização. Algumas das obras desses artistas dialogam com as da categoria Land Art por apresentar alguma intervenção no ambiente. Suas realizações mais conhecidas eram "empacotamentos" de diversos elementos naturais ou de monumentos bastante representativos, como o Reichstag, situado em Berlim, por exemplo.

As questões da fotografia dessa obra de Christo e Jeanne-Claude e da obra de Smithson diferenciam-se em alguns aspectos e igualam-se em outros. Igualam-se no sentido de que nem uma nem outra obra pode ser levada ao museu a não ser por meio da respectiva documentação, dentre as quais as fotografias. A diferença é que a obra de Smithson não apenas pode permanecer onde está como ainda permanece, ao contrário da obra de Christo e Jeanne-Claude, que, obrigatoriamente, teve que ser desfeita após um período determinado.

Outro artista ainda mais atual que se pode citar é Vik Muniz, brasileiro de renome internacional, cujas obras - constituídas dos mais diversificados materiais, como poeira, açúcar, sucata e lixo - são fotografadas, para que essas fotografias sejam expostas em seu lugar, tendo em vista a problemática ou a dificuldade de expor a obra em si (Muniz, 2007). O artista apresenta consciência de que suas obras são efêmeras e de que o que deve permanecer é sua documentação fotográfica. No caso, a fotografia toma o lugar da obra e adquire o status de obra de arte.

Muitos são os exemplos que podem ser apresentados para representar a efemeridade da obra, permanecendo apenas sua documentação, ou a impossibilidade de observação da obra que não por alguma forma de registro. Todavia, há aquelas que se tornam inviáveis de serem registradas fotograficamente, ou mesmo impossíveis. Isto é, segundo Freire (1999), tentar captar as instalações por meio das câmeras fotográficas é um problema recorrente que remete às questões relacionadas às inúmeras perspectivas. Assim, não existe uma única perspectiva para que a instalação seja abordada e cada perspectiva daria à obra um novo sentido.

\section{Conclusão}

Para responder à primeira pergunta pode-se dizer que a fotografia enquanto registro/reprodução automática das coisas e fatos, está mais para documento, ou melhor, documentação, do que para arte. A arte, de certo modo, requer outros sentidos diferentes desse reproduzir automaticamente com o fim de registrar os fatos. Não seria diferente com a fotografia de uma obra de arte; ou seja, a função é a documental. Por outro lado, é possível que o fotógrafo enquanto artista venha requerê-la enquanto sua obra de arte. Nesse sentido, seria arte pela intencionalidade do autor, do artista.

Quanto à segunda questão, o registro fotográfico não serve unicamente para relembrar a intervenção artística realizada, ou alguma obra de arte efêmera um dia exposta. Ele é, em si, uma obra de arte também, conforme a já mencionada intencionalidade artística. Se o fotógrafo/artista apresenta o registro fotográfico enquanto obra de arte, ele terá seu status como tal. Em certa medida o que a diferenciará das outras obras será seu suporte. Como exemplo citado anteriormente, muitas performances foram realizadas diante da câmera e não do público, e esses registros foram apresentados a posteriori como obras.

Reconhece-se a necessidade de um estudo mais aprofundado para que se possa responder à terceira pergunta. Por outro lado, pode-se dizer que, atualmente, as fotografias passam por processo de musealização com intuito tanto documental quanto artístico. É provável que nem todas as instituições trabalhem do mesmo modo 
e com as mesmas regras. Enquanto algumas podem tratar as fotografias como obras de arte, outras podem tratá-las unicamente como documentos. Assim sendo, confirma-se a hipótese de que as instituições têm dificuldade em estabelecer o local de guarda do registro fotográfico de determinados tipos de obra de arte contemporânea, devido a sua versatilidade.

Para a guarda, o entendimento é de que as instituições irão atribuir uma das duas funções ao registro fotográfico, documental ou estética, e definir como tratá-lo, o que não impede, é claro, de que seja posto em uma pasta específica e encaminhado para o setor que melhor apresente condições de preservação. O que é mais importante nesse caso não é o local em que ele se encontra, mas se sua catalogação no sistema de recuperação foi realizada de modo completo e detalhado, possibilitando encontrá-lo rápido e facilmente quando requisitado para os devidos fins. Ainda assim, esse é um aspecto discutível que merece melhor aprofundamento em pesquisa específica.

Por fim, o presente estudo apenas elencou alguns assuntos para debates quanto aos registros em arte contemporânea, em especial a fotografia, apontando discussões relacionadas à sua musealização, bem como à função estética e/ou documental que a ela pode ser atribuída.

\section{Colaboradores}

B.C. Rodrigues e G. Crippa contribuíram na concepção e desenho do estudo, análise de dados e redação final.

\section{Referências}

Archer, M. Arte contemporânea: uma história concisa. São Paulo: Martins Fontes, 2001.

Benjamin, W. A obra de arte na era de sua reprodutibilidade técnica. In: Benjamin, W. Magia e técnica, arte e política: ensaios sobre literatura e história cultural. 7. ed. São Paulo: Brasiliense, 1994. (Obras Escolhidas).

Buckland, M. K. Information as thing. Journal of the American Society for Information Science, v. 42, n. 5, p. 351-360, 1991. Available from: <http://people.ischool.berkeley.edu/ buckland/ thing.html>. Cited: Aug. 22, 2006.

Buckland, M. K. What is a document? Journal of American Society for Information Science, v. 48, n. 9, p. 804-809, 1997. Available from: <http://people.ischool.berkeley.edu/ buckland/ whatdoc.html>. Cited: Aug. 22, 2006.

Costa, H. Da fotografia como arte à arte como fotografia: a experiência do Museu de Arte Contemporânea da USP na década de 1970. Anais do Museu Paulista, v. 16, n. 2, p. 131-173, 2008.

Costa, L. C. O registro na arte contemporânea: inscrições de visibilidades, discursos e temporalidades como séries da obra. In: Costa, L. C. (Org.). Dispositivos de registros na arte contemporânea. Rio de Janeiro: Contra Capa Livraria, 2009.

Cotton, C. A fotografia como arte contemporânea. São Paulo: WMF Martins Fontes, 2013.

Crimp, D. Sobre as ruínas do museu. São Paulo: Martins Fontes, 2005.
Dubois, P. O ato fotográfico e outros ensaios. Campinas: Papirus, 1994.

Fervenza, H. Registros sobre deslocamentos nos registros da arte. In: Costa, L. C. (Org.). Dispositivos de registros na arte contemporânea. Rio de Janeiro: Contra Capa Livraria, 2009.

Freire, C. Poéticas do processo: arte conceitual no museu. São Paulo: Iluminuras, 1999.

Gil, A. C. Métodos e técnicas de pesquisa social. 5. ed. São Paulo: Atlas, 1999.

Gombrich, E. H. A história da arte. Rio de Janeiro: LTC, 2013.

Krauss, R. O fotográfico. Barcelona: Editorial Gustavo Gili, 2002.

Loureiro, M. L. N. M. Preservação in situ X ex situ: reflexões sobre um falso dilema. In: Seminário de Investigação em Museologia dos Países de Língua Portuguesa e Espanhola, 3., Madri, 2011. Anais eletrônicos... Madri, Espanha, 2011. Disponível em: <https://repositorio.uam.es/bitstream/handle/ 10486/11607/57448_16.pdf?sequence=1 >. Acesso em: 18 jul. 2014.

Melim, R. Performance nas artes visuais. Rio de Janeiro: Jorge Zahar, 2008.

Melim, R. Reconstruções e interpretações de performances nas artes visuais. In: Labra, D. Performance presente futuro. Rio de Janeiro: Aeroplano, 2009. v. 2. p. 44-52.

Meneses, U. T. B. Do teatro da memória ao laboratório da História: a exposição museológica e o conhecimento 
histórico. Anais do Museu Paulista: História e Cultura Material. v. 2, n. 1, p. 9-42, 1994.

Muniz, V. Reflex: Vik Muniz de A a Z. São Paulo: Cosac Naify, 2007.

Nascimento, E. N. Discursos e reflexividade: um estudo sobre a musealização da arte contemporânea. 2013. 352 f. Tese (Doutorado em Museologia) - Universidade do Porto, 2013.
Roque. M. I. R. O museu de arte perante o desafio da memória. Boletim do Museu Paraense Emílio Goeldi: Ciências Humanas, v. 7, n. 1, p. 67-85, 2012. Disponível em: <http://www.scielo. $\mathrm{br} / \mathrm{pdf} / \mathrm{bgoeldi} / \mathrm{v} 7 \mathrm{n} 1 / \mathrm{a} 06 \mathrm{v} 7 \mathrm{n} 1 . \mathrm{pdf}>$. Acesso em: $14 \mathrm{jul}$. 2014.

Rouillé, A. A fotografia: entre documento e arte contemporânea. São Paulo: Editora Senac, 2009.

Triviños, A. N. S. Introdução à pesquisa em ciências sociais: a pesquisa qualitativa em educação. São Paulo: Atlas, 1987. 